Delft University of Technology

\title{
Towards a User-Oriented Open Data Strategy
}

van Loenen, Bastiaan

DOI

10.1007/978-94-6265-261-3_3

Publication date

2018

Document Version

Final published version

Published in

Open Data Exposed

\section{Citation (APA)}

van Loenen, B. (2018). Towards a User-Oriented Open Data Strategy. In B. Van Loenen, G.

Vancauwenberghe, \& J. Crompvoets (Eds.), Open Data Exposed (pp. 33-53). (Information Technology and Law Series; Vol. 30). TMC Asser Press. https://doi.org/10.1007/978-94-6265-261-3_3

\section{Important note}

To cite this publication, please use the final published version (if applicable).

Please check the document version above.

\section{Copyright}

Other than for strictly personal use, it is not permitted to download, forward or distribute the text or part of it, without the consent of the author(s) and/or copyright holder(s), unless the work is under an open content license such as Creative Commons.

\section{Takedown policy}

Please contact us and provide details if you believe this document breaches copyrights.

We will remove access to the work immediately and investigate your claim. 
Green Open Access added to TU Delft Institutional Repository

'You share, we take care!' - Taverne project

https://www.openaccess.nl/en/you-share-we-take-care

Otherwise as indicated in the copyright section: the publisher is the copyright holder of this work and the author uses the Dutch legislation to make this work public. 


\title{
Chapter 3 \\ Towards a User-Oriented Open Data Strategy
}

\author{
Bastiaan van Loenen
}

\section{Contents}

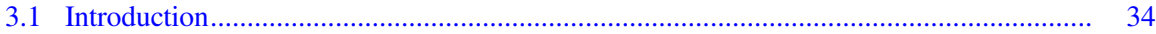

3.2 The Role of Users in the Open Data System ............................................................. 35

3.2.1 Exploring User Needs ................................................................................. 36

3.3 Design Process for a User-Oriented Open Data Approach............................................ 39

3.3.1 Step 1: Determine Your Objectives ......................................................................... 40

3.3.2 Step 2: Recognise and Identify the User ........................................................... 41

3.3.3 Step 3: Assess the Users .................................................................................. 42

3.3.4 Step 4: Involve the User .............................................................................. 42

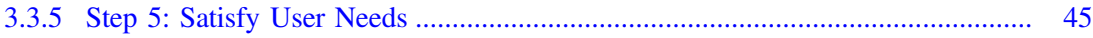

3.4 Implementing a User-Oriented Approach ................................................................. 45

3.4.1 Increasing the Efficiency of Operations of Government ……............................ 45

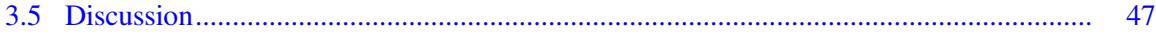

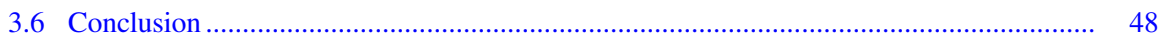

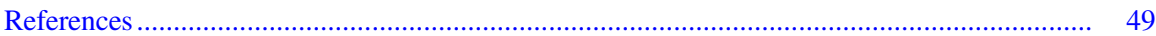

\begin{abstract}
The chapter explains that the single typical user of open government data does not exist. Therefore, data suppliers should take a five-step approach in the design of the user oriented policy: (1) define its objective(s) of open data, (2) recognise and identify the user types needed to arrive at the objectives, (3) assess the appropriateness of the identified users, (5) satisfy the needs. Although it will always be a challenging endeavour to satisfy all users to the fullest extent of their needs and/or demands, it is recommended to involve users in the decision-making processes related to open data: a shift from supply-to user-driven open data provision is a key step in open data management.
\end{abstract}

Keywords Open data $\cdot$ User $\cdot$ Strategy

B. van Loenen $(\square)$

Faculty of Architecture and the Built Environment, Knowledge Centre Open Data,

Delft University of Technology, Delft, The Netherlands

e-mail: b.vanloenen@tudelft.nl

(C) T.M.C. ASSER PRESS and the authors 2018

B. van Loenen et al. (eds.), Open Data Exposed, Information Technology and Law

Series 30, https://doi.org/10.1007/978-94-6265-261-3_3 


\subsection{Introduction}

Open data are data that can be used and reused without any (financial, legal, intellectual and technical) barriers. It may be framed as data that is free, licence free, machine-readable and provided in open format. Open data initiatives have resulted in a greater availability of (public) data that can be freely reused by anyone for any purpose.

In a very generic sense one may argue that the key to a successful open data system is the extent to which the data is being used. Or, as Onsrud and Rushton already phrased it in 1995: "the value of data comes from its use". ${ }^{1}$ Use of open data and therefore users of open data are at the core of the open data infrastructure. Without users there is no use, and without use no impact. We may assume that the more data is been used the higher its (economic or social) value.

Although the role of users is assumed to be critical for open data's success, open data initiatives are more often than not solely supplier driven. ${ }^{2}$ This means that there is currently a single direction provisioning data from governments to end users through a data portal or platform. ${ }^{3}$ Typical open data strategies seem to focus on the single typical user and provides any data that can be open in a way that the data supplier perceives as okay. As a consequence, open data providers are often not aware of the actual use and the user(s) of their data. ${ }^{4}$ What they do know (at best) is that opening up data most often results in increasing usage numbers. ${ }^{5}$ Usage numbers typically being the number of views or downloads of a dataset. ${ }^{6}$ But who exactly uses open data, for which purposes and with what benefits remains unknown in most instances. ${ }^{7}$ Government, and government researchers that aim to assess the (potential) impact of open data, lack sufficient information about who the users of their data are, what they are doing with the open data, how much they benefit from open data and, as a consequence, provide bogus data on the perceived impact of open data. ${ }^{8} \mathrm{~A}$ user driven approach should overcome these gaps in the data strategy of government. User driven efforts imply a more active, participatory or responsive level of government involvement with open data users. ${ }^{9}$ But how to arrive at a user-driven strategy if the users are unknown or highly diverse?

\footnotetext{
${ }^{1}$ Onsrud and Rushton 1995.

${ }^{2}$ Sieber and Johnson 2015; Susha 2015; Zuiderwijk-van Eijk 2015; See also McLaughlin and Nichols 1994, p. 72: "users will probably be the most mentioned group and yet actually the least considered".

${ }^{3}$ Evans and Campos 2013.

${ }^{4}$ Susha 2015; Zuiderwijk-van Eijk 2015; Harrison et al. 2012.

${ }^{5}$ Schennach 2008; Pollock 2009; Tam 2009; USGS 2012, 2014, 2018; López Romero 2016; PDOK 2016; PwC 2017.

${ }^{6}$ See for example Deloitte 2014.

${ }^{7}$ See Susha et al. 2015, p. 189; Olausson 2016.

${ }^{8}$ Janssen et al. 2012; see also Chap. 4 of this book.

${ }^{9}$ Sieber and Johnson 2015. Partly due to the unknown use, some even argue that the open data impact is very limited (see Welle Donker 2010 and 2016; Du Preez 2012; Rothenberg 2012; Bertot et al. 2012; Open data barometer 2013; Peled 2013; Algemene Rekenkamer 2014).
} 


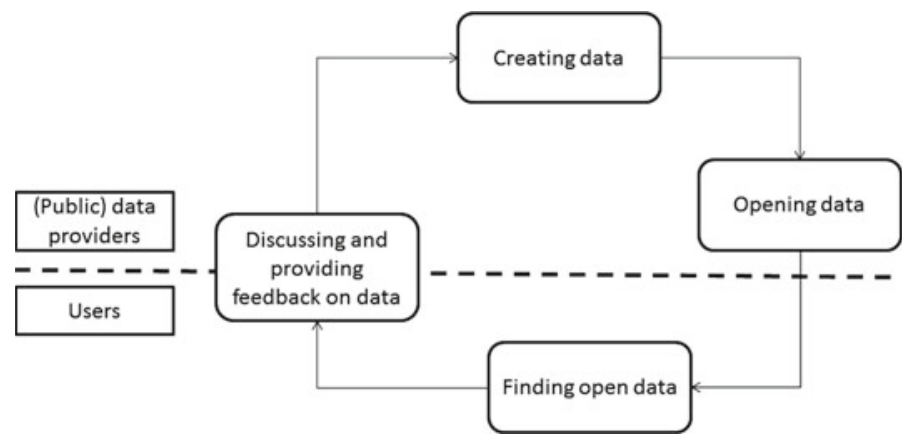

Fig. 3.1 The open data process [Source based on Janssen et al. 2012]

In this chapter, we attempt to unravel the user, arguing that a successful open data strategy starts with identifying the goals of the strategy and answering the question: which objective needs to be addressed? In Sect. 3.2, we explain the different roles that a user may have in the open data system and describe the associated user needs for each role. Section 3.3 addresses user involvement in the open data system and Sect. 3.4 provides ways to involve the user. The proposed strategy is discussed in Sect. 3.5. Section 3.6 concludes this chapter.

\subsection{The Role of Users in the Open Data System}

Parsons et al. regard data as "a key nutrient or the water that needs to flow smoothly through the ecosystem". ${ }^{10}$ Users are important enablers of the data flow. Data flows if the data satisfies the users' needs. It will not flow if it cannot be reused. Therefore, the strengths of the data flow strongly depend on the extent to which user needs are being satisfied. As such, the user is at the very core of the open data system. ${ }^{11}$ So the user is as critical to the performance of the system as the data provided.

Conceptually the open data flow follows five consecutive steps: (1) data creation or collection, (2) open data publication, (3) open data finding, (4) usage, and (5) evaluation in which the experiences with the data may be discussed with the data provider, who may improve the data (provision) accordingly (see Fig. 3.1). In this respect, users are a central component in an open data system.

The open data process focuses on the open data itself. The user may also have a role in the open data policy cycle: ${ }^{12}$ after the recognition of the need for an open data policy, (1) the open data policy will be created (identifying policy objectives and

\footnotetext{
${ }^{10}$ Parsons et al. 2011.

${ }^{11}$ See Chap. 1 of this book.

${ }^{12}$ Cf. Jann and Wegrich 2007.
} 


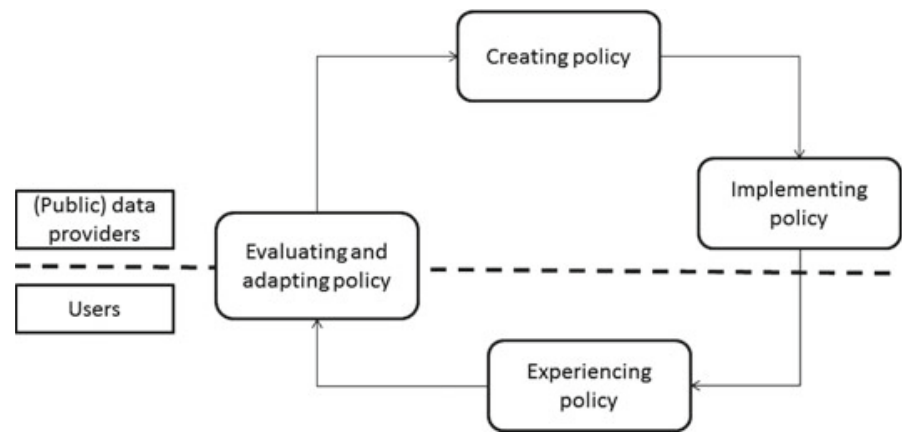

Fig. 3.2 The data policy process [Source The author]

policy formulation), (2) adopted and implemented, (3) users will experience the policy, and (4) the experiences with the open data policy may be evaluated with the data provider, who may use the evaluation to draft and implement policy alternatives (see Fig. 3.2). The open data strategy may be directed towards satisfying user needs. Implementing policies that involve users in the open data policy cycle is one way to accomplish the open data strategy.

The policy cycle performs at different (interacting) levels: varying from global to regional to national, organisational and dataset levels. At each level users can be identified and involved. But who is the user that finds, uses, and is willing to discuss the open data, and evaluates and adapts the open data policies?

\subsubsection{Exploring User Needs}

Users may decide to use the data if the data: ${ }^{13}$

1. existence is known to the user (where can it be obtained?),

2. is attainable for the user (can he use the information, and if so under what conditions, is it easy to access the data,) and

3. is fit for purpose or usable (for example, in the light of the level of aggregation, used standard, accuracy and completeness of the information, intellectually accessible). ${ }^{14}$

\footnotetext{
${ }^{13}$ See also Backx 2003; Jetzek 2017; Zuiderwijk et al. 2014; Janssen et al. 2012 MICUS Management Consulting GmbH 2008; Groot et al. 2007; National Research Council 2004; Spatial Technologies Industry Association 2001; KPMG 2001; Ravi bedrijvenplatform 2000; Meixner and Frank 1997; Onsrud and Rushton 1995; Van Loenen 2006.

${ }^{14}$ Frank and Walker 2016, p. 56 noted in their research on use by non-specialist open data users that the immediate intelligibility was often missing. These users, although very competent in their field, often found datasets hard to interpret.
} 
Only if these conditions are met a user will be able to use, for example as part of a value-added service that he wants to bring to the market. ${ }^{15}$ Although at first glance, these user requirements seem simple and straightforward, they appear to be difficult to implement. Especially since users of data are highly diverse both in their data needs, (data) skills and available resources.

A dataset may be well known for one user, while another may never have heard of it. Some expert users may find their way in the 500,000+ open datasets offered by the European Data Portal, ${ }^{16}$ other expert users may be lost. Some can afford to pay the marginal cost of dissemination, while other cannot pay a one-time $€ 168$ fee for a full download of a national building and address dataset. Some users may be satisfied with old generic static data (e.g., a map of France in 1950) while others require real-time highly detailed data (e.g., the current flow of traffic in the city centre). Some can deal with (domain) specific formats (e.g., GML) others have no knowledge of such specific formats and expect the data to be integrated automatically in the application they are using. Similar discussions are possible for the metadata, completeness of the data, the coverage of the data, the performance level of the services, the services provided, among others.

To structure the assessment of user needs, we may group users according to characteristics that they share. For example, a commercial users group, a public sector users group, an academic group and a citizens user group. However, even within these user groups of similar characteristics there may be significant differences. For example, in a group open data companies there might be two medium sized companies that enrich the data. One requires access to the raw open data. The other prefers to have access through an API. ${ }^{17}$ What should the data provider, often government, do?

In the Open Data for Open Cities project, cities are facing the issue of providing open data through downloads or services. ${ }^{18}$ It might suffice to initially satisfy the needs of the users that require raw data (data developers) through downloads, and later on provide access to the data through data services, which satisfy users that require 24/7 access to up-to-date data. In the latter instance, commercial users with products relying on the open datasets are highly likely to also require guarantees on the 24/7 availability of the open data. Guarantees that governments not always can or are unwilling to give. Other users may be okay with sometimes failing services after business hours.

Or take the example of the group 'citizen'. One citizen is using the open data to find the nearest restaurant with a clean kitchen, another would like an overview of all government expenses per neighbourhood in the city. What dataset needs to be released first? ${ }^{19}$

\footnotetext{
${ }^{15}$ See further Van Loenen and Grothe 2014.

${ }^{16}$ See https://www.europeandataportal.eu/. Accessed June 2018

${ }^{17}$ Example extracted from a 2015 Dutch open data user group meeting.

${ }^{18}$ See http://opendata4opencities.uji.es/. Accessed June 2018.

${ }^{19} \mathrm{Cf}$. "In order to understand the benefits with open data, information about use of data is required. However, little is known about what data sets are valuable to end-users (Zuiderwijk and
} 
A relatively new development is the push towards multilingual provision of open data. ${ }^{20}$ The European Data Portal is making a first attempt by also translating the metadata categories in the portal. However, such a step is not adding much compared to translating the metadata itself. One should take care, however, that in the translating process information is not lost or changed. In addition, certain concepts may be purely national and easily be misunderstood if one is unaware of this national context (see, for example, the concept of ownership of land). ${ }^{21}$ Satisfying the single typical user would, therefore, be a very difficult endeavour, at least in the short run.

The enormous variety of (potential) users may explain the difficulty that a government has in satisfying user needs. The user is very heterogeneous with regard to the purpose of use and its ability to technically, legally, financially, and intellectually use a dataset. ${ }^{22}$ Examples of differences in user characteristics that may exist are:

- purpose of use (explorer, ${ }^{23}$ aggregator, enabler, enricher, developer, ${ }^{24}$ end user); ${ }^{25}$

- nature of the user (commercial, government, scientific, citizen);

- user roles (as a tax payer, as a citizen, as a consumer) ${ }^{26}$

- user capabilities: ${ }^{27}$ (access to) (technical, creative, domain, business) skills and know-how/understanding of open data (expert knowledge and skills to laymen knowledge and skills);

- (access to) resources/funding opportunities; ${ }^{28}$

- (access to) technical connectivity; ${ }^{29}$

\footnotetext{
Janssen 2015, p. 110).” Olausson 2016; cf. 'high value datasets' in Cabinet Office 2013; European Commission 2014.

${ }^{20}$ The EU Directive on the re-use of public sector information (consolidated text) addresses the multilingual issue in Article 9: "Where possible Member States shall facilitate the cross-linguistic search for documents."

${ }^{21}$ Tiainen 2004.

${ }^{22}$ See Bovens 1999.

${ }^{23}$ These users explore the opportunities the data may have for them; they may experiment with the data (Welle Donker and van Loenen 2017) and eventually become one of the other user types.

${ }^{24}$ See Deloitte LLP 2012; Welle Donker and Van Loenen 2016 (see also Chap. 4 of this book).

${ }^{25} \mathrm{An}$ end user is someone who interacts with the data 'as is' provided directly (Doll and Torkzadeh 1988). They are not further processing the data, but rather use the data for inspection purposes [searching for facts in the data (Hivon and Titah 2017)] supporting "their engagement in civic or bureaucratic processes" (Davies 2010, p. 3; cf. 'the comparison model' in Janssen and Zuiderwijk 2014), in business planning (Davies 2010), or to address a certain personal need, such as a nearest route to the supermarket. This group includes also the 'Data to information' user type (Davies 2010), which create "a static representation and interpretation of one or more data sources, leading to visualizations, blog posts, infographics and written reports" (Davies 2010, p. 3). In practice, many users will combine the different usages categories and within the categories the needs may vary significantly.

${ }^{26}$ See Codagnone et al. 2006.

${ }^{27}$ See Jetzek et al. 2014; OECD 2011; Welle Donker and Van Loenen 2016. See also Janssen et al. 2012; Gurstein 2011; McClean 2011; NY City 2017.

${ }^{28}$ Jetzek et al. 2014; OECD 2011.

${ }^{29}$ Jetzek et al. 2014; OECD 2011.
} 
- attitude towards open data; ${ }^{30}$

- frequency of use (permanent to one-off);

- nationality (native or international user);

- understanding of the (business) opportunities; ${ }^{31}$

- among other characteristics. ${ }^{32}$

The differences in user characteristics result in an endless list of possible user requirements, which are typically subject to change. ${ }^{33}$ This implies that satisfying one (group of) user(s) does not necessarily mean that another is satisfied. Question overall remains: How to harmonise the needs of a diversity of user groups, and different qualities of individual users within these groups?

\subsection{Design Process for a User-Oriented Open Data Approach}

The overall question remains: How to harmonise the highly diverse needs of, for example, citizens, companies, entrepreneurs, civil society groups, politicians, journalists and universities? We propose a user-oriented open data strategy that should support data providers to better achieve their open data objectives. This approach consists of five main steps:

1. Determine your objectives.

2. Recognise and identify relevant user types. ${ }^{34}$

3. Assess selected users.

4. Involve the fit-for-purpose users in the policy process.

5. Satisfy user needs.

In the first step the objective of the open data initiative is determined. This is followed by a selection of the group of users that need to be addressed in order to achieve the objective: the target user (group) is identified and in Step 3 the user (group) is assessed on its qualities. In the involvement stage, Step 4, a choice will be made about how the user will be involved in the open data decision-making process(es). Finally, measures are introduced that should support the target group in their open data activities.

\footnotetext{
${ }^{30}$ NY City 2017.

${ }^{31}$ Welle Donker and Van Loenen 2016. See also Janssen et al. 2012 Gurstein 2011; McClean 2011.

${ }^{32}$ See also Susha et al. 2015.

${ }^{33}$ See Ruijer et al. 2017, p. 48

${ }^{34}$ See also Open Data Institute 2015.
} 


\subsubsection{Step 1: Determine Your Objectives}

A first step in the design of a user oriented approach is to define the goals that the data supplier aims to achieve with open data. Open data is often promoted for its potential impact on economic value creation. ${ }^{35}$ However, businesses using open data to innovate are only a fraction of the total amount of users. ${ }^{36}$ To fully grasp the user of open data, one should assess the use across the entire open data value chain including not only use by commercial enterprises but also internal use in government, use in academia and research institutes, use by businesses for their internal processes, use by businesses for developing new products and services, and also use by citizens for their individual purposes. Therefore, open (government) data should not only be associated with realizing ambitions of increasing the economic value by companies creating innovative products and services using open data as a resource. ${ }^{37,38}$ In general, the concept of open data serves four distinguishing higher objectives:

1. increasing transparency, and accountability; ${ }^{39}$

2. fostering economic and social value creation; ${ }^{40}$

3. increasing the efficiency and effectiveness of operations of government, ${ }^{41}$ and

4. stimulating citizen empowerment. ${ }^{42}$

Typically, open data initiatives either do not acknowledge a clear objective or implicitly refer to all objectives. ${ }^{43}$ It will, then, be difficult to identify a clear user group. The resulting wide variety of (potential) users or user groups make the design of a user oriented open data strategy complex. It is no surprise to note that many governments wonder how to satisfy the specific needs of a wide variety of users, and user groups. ${ }^{44}$

So, in addressing user needs it is critical to be aware of which user one should address. The identification of the objective(s) of the open data initiative will be a

\footnotetext{
${ }^{35}$ See, for example, European Commission 2010, 2011.

${ }^{36}$ See Bates 2012 on the "the PSI re-use industry". He argues that the open government data community is not a homogeneous mass. In addition to multinational corporations and SMEs, also civic hackers, journalists and independent developers use open data. In addition Van Loenen et al. (2017) found that citizens take a much bigger share of the total open data use than previously assumed.

${ }^{37}$ E.g. Omidyar Network 2014; Dekkers et al. 2006; Pira et al. 2000; Vickery 2011.

${ }^{38}$ Also, criticasters of open data that have expressed their disappointment in the impact of open data, most often refer to the impact on innovation/economy (see Du Preez 2012; Rothenberg 2012; Algemene Rekenkamer 2014; see also Hopf et al. 2017), which is only one of the four higher objectives that open data may contribute to.

${ }^{39}$ Davies 2010; Huijboom and Van den Broek 2011; Cabinet Office 2013.

${ }^{40}$ World Bank Group 2015; Cabinet Office 2013.

${ }^{41}$ Davies 2010; Huijboom and Van den Broek 2011; Susha et al. 2015.

${ }^{42}$ Uhlir 2009; Davies 2010; Jetzek 2013; Susha et al. 2015.

${ }^{43}$ See, for example, Cabinet Office 2015.

${ }^{44}$ See, for example, Dutch government 2015.
} 
first step in this process. With a clear objective, the appropriate user group can be identified. ${ }^{45}$ If the objective is to increase transparency of public processes, then the target user group may be data journalists and citizens. If the objective aims at stimulating innovation and economic value creation, then value adding companies may need to be identified, involved and addressed. So, the objective of open data determines to some extent the users that need to be satisfied. Therefore, the very first step would be to clearly identify the objectives of open data. The next step is to recognize and identify users of open data.

\subsubsection{Step 2: Recognise and Identify the User}

After defining the goals of an open data initiative and recognising the associated user groups, the individual users need to be identified. If the data has been provided with restrictive contracts, then one may build on the input of these (contractual) clients as a starting point. In other instances, one may rely on one of the following alternatives for identifying open data users: ${ }^{46}$

- Mandatory user registration. To bridge the gap between provider and user of open data, some organisations require users to register for access to the open data (see for example the Danish Mapping Agency KMS and the UK Consumer Data Research Centre data portal). It provides them with some information on the use(r) and potentially enables them to ask for feedback and input.

- Voluntary registration of the user. The second approach is identical to the first approach, with the difference that the registration is voluntary.

- Social media channels. Approach three uses social media as a way to link data providers and users. Users and sometimes also data providers, can start social media groups around a specific dataset. Data providers may also explore social media channels to identify users of their data, for example through blogs of users.

- Establishing a user group. The fourth approach gains insights from a frequently meeting user group. Establishing a user group attracts well-informed users but leaves out on new user groups (e.g. start-ups), since these are unknown, not visible or not organised in a formal manner, such as through (business) associations and such like.

- Additional service provision. A data provider may be in contact with data users through the provision of additional open data services (e.g. a service notifying users of new dataset updates, a data quality feedback service or a newsfeed service) or through a contractual relation for additional services.

\footnotetext{
${ }^{45}$ If we want to establish an open data user oriented strategy we need to know more about the user. However, as a matter of principle, the user of open data is unknown (Stott 2014). So, in order to arrive at an open data user oriented strategy the user needs to become visible. This implies that the open data provision may need to become less open: how the development of a user-oriented data agenda/ strategy is a contradiction in terminus.

${ }^{46}$ This section draws on Van Loenen et al. 2017.
} 
- Organising (ad hoc) events. Data providers may organise hackathons, data rallies, etcetera, to explore the opportunities of open data and to become acquainted with the users of the data.

- Log files analytics. Data providers may study the log files of the platform where the data is provided. ${ }^{47}$ For example, in China, the Guiyang Government Data Open Platform automatically traces and visualize the visitors. ${ }^{48}$

- Purposely having a server down. Regular users will call the data provider and make themselves known.

Once the user categories whose needs need to be addressed are known, the users relevant for the objective can be selected and invited for involvement in the open data system.

\subsubsection{Step 3: Assess the Users}

Once the users are identified, the data suppliers may want to assess the fitness of the user. This fitness assessment may involve the level of attainability of the user (are they available, do they want to contribute (motivation), ${ }^{49}$ and can they contribute (are they a legal representative and are they allowed to share opinions)?

Not all users may want to participate. As one user replied to a request to be interviewed for an open data user needs study: "If you will compensate my hours, I will be happy to participate. My hourly rate is 95 euro".

A second criterion is the extent to which the input of the user is assessed to be usable: are they knowledgeable, are they connected to the target community and can they represent a community, are they influential within their community, ${ }^{50}$ are they 'impartial'?

Other criteria may be used depending on the circumstances of the case.

\subsubsection{Step 4: Involve the User}

The user can be involved in many ways in the public decision making process on open data. Based on the public participation model of Arnstein, ${ }^{51}$ Olausson distinguished

\footnotetext{
${ }^{47}$ See Van Loenen et al. 2017.

${ }^{48}$ See Chap. 12 of this book.

${ }^{49}$ See Ruijver et al. 2017.

${ }^{50}$ See NYC Open Data 2017.

${ }^{51}$ Arnstein 1969.
} 


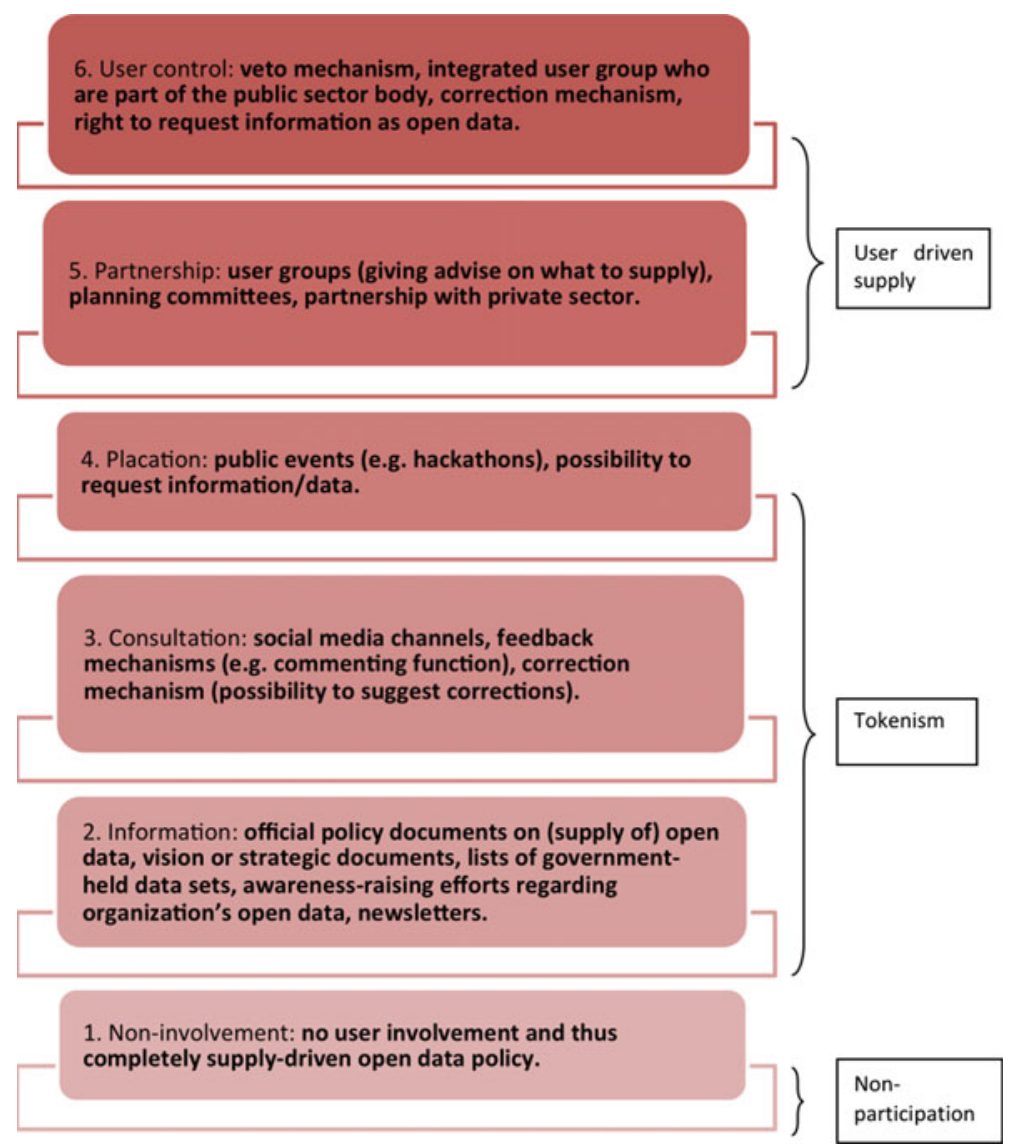

Fig. 3.3 Modified ladder of user involvement in supply of open data [Source Olausson 2016, p. 49]

in her 'ladder of user involvement in open data supply' (see Fig. 3.3) six levels of user involvement. $^{52}$

1. user control;

2. partnership;

3. placation;

4. consultation;

5. information;

6. non-involvement.

\footnotetext{
${ }^{52}$ See Olausson 2016, p. 49. Although the model of Olausson specifically addresses user involvement in open data supply, it is sufficiently generic for this discussion as a model of user involvement in the entire open data system including the open data process and the open data policy cycle.
} 
At the highest level, user control, users control the open data system decision making process: they determine the direction, control the budget and are responsibility for the performance of the system. A lighter version of user control would be that in addition to being consulted in user groups or otherwise, users have the possibility to veto decisions. For example, at this level, users may determine and, if necessary, enforce that a data supplier provides a dataset as open data.

At the partnership level, there is a trade-off between users and suppliers of open data. $^{53}$ Examples of partnerships are user groups of open data or public-partnerships. At this level, users may take a policy advisor role, which is discussed by the decision-making platform where both users and providers are represented. For example, users decide together with the data provider to provide a dataset as open data.

At the placation level, there is some influence of the user on the direction of the open data system through, for example, public events. At this level, users have the right to advice, which might be incorporated in the final decision taken by the open data supplier/government responsible for open data. For example, users advise to provide a specific dataset as open data.

At the consultation level, users are consulted, "but lack any mechanism of ensuring that this input is taken into account". 54 At this level, users are consulted about their demands, for example which dataset they would like to be released as open data. Users may also feedback on the fitness for use of the dataset. ${ }^{55}$ Similarly, the user may advise on the performance of the open data system as whole or on its subsystems or components (policy, standards, metadata, data quality, misuse, open data infrastructure, etcetera).

At the information level, users are informed about open data through providing newsletters, policy documents, published on websites, social media, but also about awareness raising events. For example, they will be notified about the release of a new open dataset.

Finally, the last level is the non-involvement level where there is no interaction, one-way or two ways, between open data users and the rest of the system.

Depending on the issue ${ }^{56}$ sometimes a 'user in control' modus might be appropriate. ${ }^{57}$ In other instances, informing users will be sufficient. For some topics a focus group approach may work, ${ }^{58}$ for others the full plethora of user categories needs to be involved.

\footnotetext{
${ }^{53}$ Olausson 2016, citing Arnstein 1969.

${ }^{54}$ Olausson 2016, p. 26.

${ }^{55}$ See, for example, Zuiderwijk-van Eijk 2015 proposing a 5 and 10 star data quality review system where users could indicate the fit for their purpose of a dataset.

${ }^{56}$ The model can be applied at different hierarchal levels (global, regional, national, organisational and dataset) and also to each single step in the open data value chain.

${ }^{57}$ See Welle Donker and Van Loenen 2016.

${ }^{58}$ E.g. G2G, or G2B, or B2B, or C2C (citizen to citizen).
} 


\subsubsection{Step 5: Satisfy User Needs}

The first four steps should result in a situation where the needs of (a specific group of) open data users is satisfied. What this implies depends on the specific circumstances of the case. Section 3.4 elaborates on this aspect for the objective efficiency of operations.

\subsection{Implementing a User-Oriented Approach}

In this section, we provide an example of how the designed user oriented approach may be implemented in practice. It should be noted that open data initiatives in practice may not be able to copy the exact example due to the fact that each initiative is likely to develop and perform in a unique environment with unique requirements for the implementation of the approach. As such, the approach may be used as guidance to arrive at a user oriented approach.

Our approach starts with the data supplier, often government. Why do they want to provide the data as open data, what do they want to achieve? And how may user involvement help them to arrive at the envisioned situation?

In Sect. 3.3, we summarised the four open data objectives:

1. promoting transparency and accountability;

2. fostering economic and social value creation;

3. increasing the efficiency and effectiveness of operations of government;

4. stimulating citizen empowerment.

In the next section, we provide an example for the objective of increasing the efficiency of government operations.

\subsubsection{Increasing the Efficiency of Operations of Government}

\section{Determine objective}

Suppliers that aim at increasing their efficiency may use users input to:

- identify duplicate datasets;

- provide feedback on the quality of the data, its provision and policies.

Efficiency of operations typically concerns reducing duplicate data collection and processing efforts in the supplier organisation, but can also be applicable to the user side. It further implies minimizing transaction costs at both the supplier and user sides, since open data are directly available without any administrative struggles (e.g., contract negotiations, enforcement of contractual terms) and delays. 
Opening data may benefit the quality of the dataset. ${ }^{59}$ The more the data are used, the more likely it is that errors are identified and corrected. ${ }^{60}$ With appropriate feedback mechanisms in place, the user may report errors and/or fix errors directly in the data.

\section{Recognise and 3. Identify user type}

For this objective one may recognise and identify users wanting to improve the efficiency of government operations who are using open data to provide services in/ to the public sector and/or seeking technologically driven improvement of government operations or functioning. ${ }^{6}$

\section{User involvement}

Users to be involved to arrive at this objective, may be both users residing within government as well as in businesses. They may be involved by information and through consultation, either in advisory boards or otherwise.

\section{User satisfaction}

In addition to the generic requirements for open data provision (findable, attainable and useful), ${ }^{62}$ users should be provided with user-friendly means to provide input.

In facilitating feedback to the data quality, open data suppliers may use or choose several available feedback mechanisms, ${ }^{63}$ such as a contact point (e.g., a help desk), a web form, through social media, by following the blog of known data users, ${ }^{64}$ or by allowing the user to directly fix the error in the data. ${ }^{65}$ In addition, formal complaint procedures may be used for the feedback purpose. ${ }^{66}$ Social media would allow for interactivity where the reporting is available to all, other users can support a reported error or provide suggestions to fix it. Ideally, a two way interaction between the provider and user of the data is established. ${ }^{67}$

Prerequisite is that the data provider facilitates feedback and responds timely. ${ }^{68}$ As one user noted: "I love to give feedback on the quality of the open data, but waiting for four months for an answer is killing my motivation for future feedback actions."

\footnotetext{
${ }^{59}$ Janssen et al. 2012.

${ }^{60}$ See, for example, Holley 2009; RDW 2015; Zuiderwijk and Janssen 2015, p. 113.

${ }^{61}$ Davies 2010.

${ }^{62}$ See also Backx 2003; Jetzek 2017; Zuiderwijk et al. 2014; Janssen et al. 2012; MICUS Management Consulting GmbH 2008; Groot et al. 2007; National Research Council 2004; Spatial Technologies Industry Association 2001; KPMG 2001; Ravi bedrijvenplatform 2000; Meixner and Frank 1997; Onsrud and Rushton 1995; Van Loenen 2006.

${ }^{63}$ See also Eckhartz and Folmer 2015.

${ }^{64}$ As one user stated: "I will post my findings on my blog. It is up to government to check it. If they follow me on social media" (Van Loenen et al. 2016).

${ }^{65}$ See OpenStreetMap.

${ }^{66}$ Eckhartz and Folmer 2015, p. 36.

${ }^{67}$ See Vancauwenberghe and Van Loenen 2018, p. 26.

${ }^{68}$ Van Loenen and Welle Donker 2014. See also Olausson 2016, p. 123; Ruijer et al. 2017, p. 46.
} 


\subsection{Discussion}

In the proposed approach we have put the government data supplier perspective central: how may users contribute to the government perspective? Ideally, this perspective aligns with the perspective of specific users (or user groups). Therefore, we may regard the proposed approach as semi-user oriented. In a truly user oriented approach, the user would be in control. It will start with the objectives of the users, not with the objectives of the providers. Such an approach is difficult to implement, since a single typical user does not exist and a single strategy to address this single typical user is likely to fail. One approach may be to consciously include the multiplicity of users and their needs in the open data objectives. Through the development of open data user archetypes (of existing or envisioned user groups) and specific policies for each of the archetypes, a user driven approach may be introduced. ${ }^{69}$ Existing users that meet the characteristics of an archetype may then be targeted and involved in the open data process.

This chapter did not discuss ways to motivate users to become involved ${ }^{70}$ nor did we discuss the level of involvement. At a strategic level, a different type of users is required than at an operational (dataset) level. At strategic level, the entire open data system may be subject of discussion including the context in which the open data system has to operate. At the operational levels, users may only want to obtain the open data at ease or use the open data infrastructure to upload their own data. The current approach does not explicitly address these differences.

Further issue on the user involvement is the awareness that some user group representatives might be over-representing a group and sometimes specific user groups may be overrepresented. ${ }^{71}$ In addition, the 'less-likely' or potential users, ${ }^{72}$ for example, may not be addressed by vested interests and those representing them. And what should government do if the open data are frequently used for other purposes than the data were released for as open data? Should these users also be involved?

Despite the difficult of the non-existence of a single typical user, it goes without saying that open data can only meet any of its objectives if users are involved in open data system decision making processes, either at operational level or at levels. Key is that a mutually beneficial relationship between open data providers and users is developed. ${ }^{73}$ As with Olausson: ${ }^{74}$ "Following up on input and having a more active dialogue with users is thus the essential thing. The form according to which this takes place is less important. What is important is instead that user demand is given a central place in the decision on the supply of open data". 75

\footnotetext{
${ }^{69}$ Or user personas: see, for example, NY City 2017.

${ }^{70}$ See, for example, Antonini et al. 2015.

${ }^{71}$ And similarly underrepresented. Typically the ambiguous concept of citizen as a user results in no citizen representation in open data infrastructure discussions. See also Bates 2012.

${ }^{72}$ NY City 2017.

${ }^{73}$ NY City 2017.

${ }^{74}$ Olausson 2016, p. 125.

${ }^{75}$ Olausson 2016.
} 
In order for a user driven open data system to work, the 'right' users need to be involved. Right in between parentheses, since the single typical user does not exist. Government or the open data system power holder should determine on a case by case basis which users should be involved.

The proposed strategy for the design of an open data user oriented approach in some cases might be too complex to implement. A more pragmatic start may then be helpful. For example, if the data supplier defines the open data objective in terms of improving the functioning of government, then he/she may first focus on one government function and for that function define key questions that government would like to be answered by the open data community. This 'think big, act small' approach may be extended if successful to other questions, issues, problems and objectives. ${ }^{76}$ This is what Susha et al. call from demand-driven to problem-driven to enable real-life problem solving. ${ }^{77}$

\subsection{Conclusion}

In this chapter, we addressed the user in the open data system. The chapter explains that the single typical user does not exist. In addressing the user of their open data, providers need to be more specific in discussions about satisfying user needs, involving the user and taking the user seriously. Acknowledging that the single typical user does not exist implies a conclusion that it is very difficult to design strategies that satisfy all users at once in a single strategy. This chapter argues that open data strategies should be linked to arriving at one or more of the higher open data objectives of (1) increasing transparency and accountability, (2) fostering economic and social value creation, (3) increasing the efficiency and effectiveness of operations of government, and (4) stimulating citizen empowerment. Even then, it would be difficult to include all users.

The data supplier should take a five step approach in the design of the user oriented policy: (1) define the objective(s) of open data, (2) recognise and identify the user types needed to arrive at the objectives, (3) assess the appropriateness of the identified users, (5) satisfy the needs. In each step there are choices to be made depending on the specific circumstances of the case.

It will be a major challenge to serve all users to the fullest extent. But involvement of users should be considered at all times by open data suppliers to fully understand and promote the performance of the current open data systems and their future enhancements.

\footnotetext{
${ }^{76}$ Cf. Susha et al. 2015.

${ }^{77}$ Susha et al. 2015, p. 201: "Bring together problem-owner, actors with ideas how to solve the problem and those with skills to manipulate open data [necessary to solve the problem]".
} 


\section{References}

Algemene Rekenkamer (2014) Trendrapport open data

Antonini M, Hogg MA, Mannetti L, Barbieri B, Wagoner JA (2015) Motivating Citizens to Participate in Public Policymaking: Identification, Trust and Cost-Benefit Analyses. Journal of Social and Political Psychology 3(2):131-147

Arnstein SR (1969) A ladder of citizen participation. Journal of the American Institute of Planners 35(4):216-224

Backx M (2003) Gebouwgegevens redden levens [Building data save lives]. MSc. Thesis, Delft University of Technology, Delft

Bates J (2012) This is what modern deregulation looks like: co-optation and contestation in the shaping of the UK's Open Government Data Initiative. The Journal of Community Informatics $8(2)$

Bertot JC, McDermott P, Smith T (2012) Measurement of Open Government: Metrics and Process. 45th Hawaii International Conference on System Sciences, pp 2491-2499

Bovens MAP (1999) Informatierechten [Information rights]. Preadvies voor de Nederlandse Vereniging voor de Wijsbegeerte van het Recht. Nederlands Tijdschrift voor Rechtsfilosofie en Rechtstheorie (R\&R) 2:102-124

Cabinet Office (2013) Policy Paper: G8 Open Data Charter and Technical Annex, 18 June 2013

Cabinet Office (2015) Policy Paper 2010 to 2015 Government Policy: Government Transparency and Accountability

Codagnone C, Caldarelli L, Cilli V, Galasso G, Zanchi F (2006) Compendium to the Measurement Framework. eGEP Project. DG Information Society, Brussels

Davies T (2010) Open data, democracy and public sector reform: A look at open government data use from data gov.uk. MSc. Thesis, Oxford Internet Institute

Dekkers M, Polman F, te Velde R, de Vries M (2006) Measuring European Public Sector Information Resources (MEPSIR) Study. Final report of study on exploitation of public sector information - Benchmarking of EU framework conditions

Deloitte LLP (2012) Open Growth: Stimulating demand for open data in the UK. A briefing note from Deloitte Analytics. Deloitte Touche Tohmatsu Limited, London

Deloitte (2014) Open Growth-Stimulating Demand for Open Data in the UK. A Briefing Note from Deloitte Analytics. Deloitte LLP, UK

Doll WJ, Torkzadeh G (1988) The Measurement of End-User Computing Satisfaction. MIS Quarterly 12(2):259-274

Du Preez D (2012) Prime Minister's special envoy 'disappointed' with open data use. Computerworld UK

Dutch Government (2015) Nationale open data agenda 2016

Eckartz SM, Folmer EJA (2015) BOMOD: Management and development model for open data. http://publications.tno.nl/publication/34616703/ATAycW/eckartz-2015-bomod.pdf

European Commission (2010) Communication from the Commission of 19 May 2010 to the European Parliament, the Council, the European Economic and Social Committee and the Committee of the Regions - A Digital Agenda for Europe COM(2010) 245 final

European Commission (2011) Open data An engine for innovation, growth and transparent governance COM (2011) 882 final

European Commission (2014) Commission notice - Guidelines on recommended standard licences, datasets and charging for the reuse of documents. OJ, 2014, C240/01

Evans AM, Campos A (2013) Open Government Initiatives: Challenges of Citizen Participation. Journal of Policy Analysis and Management 32(1):172-185 
Frank M, Walker J (2016) User Centred Methods for Measuring the Value of Open Data. The Journal of Community Informatics 12(2):47-68

Groot N, Bregt A, Crompvoets J, Pluijmers Y (2007) Toegankelijkheid publieke geodata vooral gehinderd door juridische barrières [Accessibility of public sector geodata mostly hampered by legal barriers]. VI Matrix 15(8):6-8

Gurstein M (2011) Open Data: Empowering the empowered or effective data use for everyone? First Monday 16(2)

Harrison TM, Pardo TA, Cook M (2012) Creating Open Government Ecosystems: A Research and Development Agenda. Future Internet 4:900-928

Hivon J, Titah R (2017) Conceptualizing citizen participation in open data use at the city level. Transforming Government: People, Process and Policy 11(1):99-118

Holley R (2009) Many Hands Make Light Work: Public Collaborative OCR Text Correction in Australian Historic Newspapers, National Library of Australia. http://www.nla.gov.au/ndp/ project_details/documents/ANDP_ManyHands.pdf. Accessed May 2018

Hopf K, Riechel S, Sodenkamp M, Staake T (2017) Predictive Customer Data Analytics - The Value of Public Statistical Data and the Geographic Model Transferability. 38th International Conference on Information Systems (ICIS), Seoul, South Korea

Huijboom N, van den Broek T (2011) Open Data: an international comparison of strategies. European Journal of ePractice 12:4-16

Jann W, Wegrich K (2007) Theories of the policy cycle, Chapter 4. In: Fischer F, Miller GJ, Sidney MS (eds) Handbook of Public Policy Analysis: Theory, Politics and Methods, pp. 43-62

Janssen M, Charalabidis Y, Zuiderwijk A (2012) Benefits, Adoption Barriers and Myths of Open Data and Open Government. Information Systems Management (ISM) 29(4):258-268

Janssen M, Zuiderwijk A (2014) Infomediary Business Models for Connecting Open Data Providers and Users. Social Science Computer Review 32(5):694-711

Jetzek T (2013) The Value of Open Government Data. Geoforum Perspectiv 12(23):47-56

Jetzek T (2017) Innovation in the Open Data Ecosystem: Exploring the Role of Real Options Thinking and Multi-sided Platforms for Sustainable Value Generation through Open Data. In: Carayannis EG, Sindakis S (eds) Analytics, Innovation, and Excellence-Driven Enterprise Sustainability. Palgrave Studies in Democracy, Innovation, and Entrepreneurship for Growth, Palgrave Macmillan, pp. 137-168

Jetzek T, Avital M, Bjørn-Andersen N (2014) Generating Sustainable Value from Open Data in a Sharing Society. IFIP WG 8.6 International Conference on Transfer and Diffusion of IT, TDIT 2014, Aalborg, March 2014

KPMG Consulting Inc. [Sears G] (2001) Geospatial Data Policy Study. GeoConnections Policy Advisory Node. GeoConnections, Ottawa

López Romero E (2016) Data Accesibility of Geospatial Reference Information. Presentation at the 129th EuroSDR Board of Delegates Meeting, Madrid, 19 October 2016

McClean T (2011) Not with a Bang but a Whimper: The Politics of Accountability and Open Data in the UK. APSA Annual Meeting

McLaughlin J, Nichols S (1994) Developing a National Spatial Data Infrastructure. Journal of Surveying Engineering 120(2):62-76

Meixner H, Frank AU (1997) Study on policy issues relating to geographic information in Europe. IMPACT program. European Commission

MICUS Management Consulting GmbH (2008) Assessment of the re-use of Public Sector Information (PSI) in the Geographic Information. Meteorological Information and Legal Information Sectors. European Commission

National Research Council (2004) Licensing Geographic Data and Services. National Academies Press, Washington DC 
NY City Open Data (2017) Understanding the Users of Open Data Research Findings. https:// opendata.cityofnewyork.us/wp-content/uploads/2017/07/Understanding-the-Users-of-OpenData_Reboot.pdf. Accessed May 2018

OECD [Organisation for Economic Co-Operation and Development] (2011) Skills for innovation and research. https://doi.org/10.1787/9789264097490-en

Olausson KRAA (2016) A step towards aligning supply and demand? - User involvement in supply of open data among ten Dutch public sector bodies. MSc. Thesis, Utrecht University

Omidyar Network (2014) Open for Business: How open data can help achieve the G20 growth target. A Lateral Economics Report commissioned by Omidyar Network

Onsrud HJ, Rushton G (1995) Sharing geographic information, 1st edn. Routledge

Open Data Barometer (2013) 2013 Global Report. WWW Foundation. ODI

Open Data Institute (2015) A guide to the Open Data Maturity Model; Assessing your open data publishing and use. Technical report

Parsons MA, Godøy Ø, LeDrew E, de Bruin TF, Danis B, Tomlinson S, Carlson D (2011) A conceptual framework for managing very diverse data for complex, interdisciplinary science. Journal of Information Science 37(6):555-569

PDOK (2016) Rapportage Q4 2016. https://www.pdok.nl/nl/actueel/rapportages. Accessed May 2018

Peled A (2013) Re-Designing open data 2.0. In: Parycek P, Edelmann N (eds) Conference for e-Democracy and Open Government. Edition Donau-Universitat Krems, Krems, pp. 243-257

Pira International Ltd., University of East Anglia and KnowledgeView Ltd. (2000) Commercial exploitation of Europe's public sector information - Final report. European Commission Directorate General for the Information Society

Pollock R (2009) The Economics of Public Sector Information. Cambridge Working Papers E 0920. May, p. 35

PwC (2017) Effekten af de frie geodata - Eftermåling; Styrelsen for Dataforsyning og Effektivisering [Impact of open geographic data - follow up study]. Report commenced by Danish government

Ravi bedrijvenplatform (2000) Economische effecten van laagdrempelige beschikkingstelling van overheidsinformatie [Economic effects of making public sector information readily available]. Ravi bedrijvenplatform, Amersfoort, The Netherlands

RDW (2015) Jaarverslag 2014 [Annual report 2014]. http://jaarverslag.rdw.nl/Documents/ Wettelijk\%20Jaarverslag\%202014.pdf

Rothenberg J (2012) Case study International Benchmark; Open data and use of standards. http:// www.forumstandaardisatie.nl/fileadmin/os/documenten/Internationale_benchmark_v1_03_ final.pdf. Accessed May 2018

Ruijer E, Grimmelikhuijsen S, Meijer A (2017) Open data for democracy: Developing a theoretical framework for open data use. Government Information Quarterly 34:45-52

Schennach G (2008) Reducing charges for national geographic reference data in AustriaePSI+. Workshop. Brussels, June

Sieber RE, Johnson PA (2015) Civic open data at a crossroads: Dominant models and current challenges. Government Information Quarterly 32(3):308-315

Spatial Technologies Industry Association (2001) Phase 1 report: Increase private sector awareness of, and enthusiastic participation in the National Spatial Data Infrastructure (NSDI). FGDC, Washington DC

Stott A (2014) [od-discuss] Registration for accessing open datasets. https://lists.okfn.org/ pipermail/oddiscuss/2014-October/001083.html. Accessed May 2018

Susha I (2015) Participation in Open Government. Orebro Studies in Informatics 8. Doctoral Dissertation 
Susha I, Grönlund Å, Janssen M (2015) Organizational measures to stimulate user engagement with open data. Transforming Government: People, Process and Policy 9:181-206

Tam S-M (2009) Australian Bureau of Statistics, Informing the Nation - Open Access to Statistical Information. Paper presented to the United Nations Economic Commission for Europe Work Session on the Communication and Dissemination of Statistics, Poland, May

Tiainen E (2004) Directions in Modeling Land Registration and Cadastre Domain; Aspects of EULIS glossary approach, semantics and information services. Joint FIG Commission 7 and COST Action G9 Workshop on Standardization in the Cadastral Domain, Bamberg, Germany

Uhlir P (2009) The socioeconomic effects of public sector information on digital networks toward a better understanding of different access and reuse policies workshop summary. In: Uhlir P, The Socioeconomic Effects of Public Sector Information on Digital Networks. The National Academies Press

USGS (2012) September 4, 2012 - 9 million Landsat downloads and counting. https://landsat.usgs. gov/september-4-2012-9-million-landsat-downloadsand-counting. Accessed May 2018

USGS (2014) Landsat Update - Volume 8 Issue 2 2014. Landsat Downloads top 17 million. https://landsat.usgs.gov/landsat-update-volume-8-issue-2-2014. Accessed May 2018

USGS (2018) April 20, 2018 - 10th Anniversary of Imagery for Everyone; more than 75 million downloads. https://landsat.usgs.gov/april-20-2018-10th-anniversary-imagery-everyone. Accessed August 2018

Vancauwenberghe G, van Loenen B (2018) Exploring the Emergence of Open Spatial Data Infrastructures: Analysis of Recent Developments and Trends in Europe, Chapter 2. In: Saeed S, Ramayah T, Mahmood Z (eds) User Centric E-Government. Springer, pp. 23-46

Van Loenen B (2006) Developing Geographic Information Infrastructures: the role of information Policies. Delft University of Technology, Delft

Van Loenen B, Grothe M (2014) INSPIRE Empowers Re-Use of Public Sector Information. International Journal of Spatial Data Infrastructures Research 9:86-106

Van Loenen B, Welle Donker F (2014) Stand in opendataland [State of open data land]. Research report for Dutch Ministry of Internal Affairs and Kingdom Relations and the Ministry of Infrastructure and Environment

Van Loenen B, Welle Donker F, Braggaar R (2016) Stand in open dataland [State of open data land]. Research report for Dutch Ministry of Economic Affairs

Van Loenen B, Ubacht J, Labots W, Zuiderwijk-van Eijk A (2017) Log File Analytics for Gaining Insight into Actual Use of Open Data. Proceedings of the 17th European Conference on Digital Government. In: Borges V, Dias Rouco JC (eds) Academic Conferences and Publishing International Limited, Lisbon, pp. 238-246

Vickery G (2011) Review of recent studies on PSI reuse and related market developments. Information Economics. Paris

Welle Donker F (2010) Public sector information access policies in Europe. In: Fitzgerald B (ed) Access to Public Sector Information: Law, Technology \& Policy. Volume 1. Sydney University Press, Sydney, pp. 253-279

Welle Donker F (2016) From access to re-use: a user's perspective on public sector information availability. Delft University of Technology, Delft

Welle Donker F, van Loenen B (2016) Sustainable Business Models for Public Sector Open Data Providers, JeDEM eJournal of eDemocracy and Open Government 8(1):28-61

Welle Donker F, van Loenen B (2017) How to assess the success of the open data ecosystem? International Journal of Digital Earth 10(3):284-306

World Bank Group (2015) Proposal for Sustainable Development Goals. https:// sustainabledevelopment.un.org/focussdgs.html. Accessed May 2018 
Zuiderwijk A, Janssen M (2015) Towards decision support for disclosing data: Closed or open data? Information Polity 20(2/3):103-117

Zuiderwijk A, Helbig N, Gil-García JR, Janssen M (2014) Guest Editors' Introduction. Innovation Through Open Data: A Review of the State-of-the-Art and an Emerging Research Agenda. Journal of Theoretical and Applied Electronic Commerce Research 9(2):I-XIII

Zuiderwijk-van Eijk AMG (2015) Open data infrastructures: The design of an infrastructure to enhance the coordination of open data use. Delft University of Technology, Delft 